\title{
ESTIMATE OF LOCA-FI PLENUM PRESSURE UNCERTAINTY FOR A FIVE-RING RELAP5 PRODUCTION REACTOR MODEL (U)
}

by

D. P. Griggs

ir.

Westinghouse Savannah River Company

Savannah River Site

Aiken, South Carolina 29808

This paper was prepared in connection with work done under the above contract number with the U. S.

Department of Energy. By acceptance of this paper, the publisher and/or recipient acknowledges the U.S. Government's right to retain a nonexclusive, royalty-free license in and to any copyright covering this paper, along with the right to reproduce and to authorize others to reproduce all or part of the copyrighted paper.

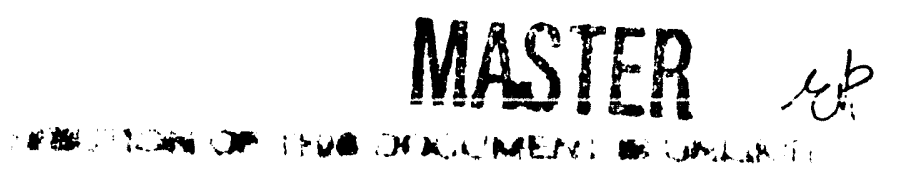




\section{NRTSC \\ NUCLEAR REACTOR TECHNOLOGY AND SCIENTIFIC COMPUTATIONS}

\author{
KEYWORDS: LOCA \\ FLOW INSTABILITY \\ RELAP5 \\ K REACTOR \\ RETENTION: PERMANENT
}

\section{ESTIMATE OF LOCA-FI PLENUM PRESSURE UNCERTAINTY FOR A FIVE-RING RELAPS PRODUCTION REACTOR MODEL}

(U)

by

D. P. GRIGGS

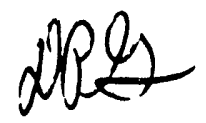

ISSUED: MARCH, 1993

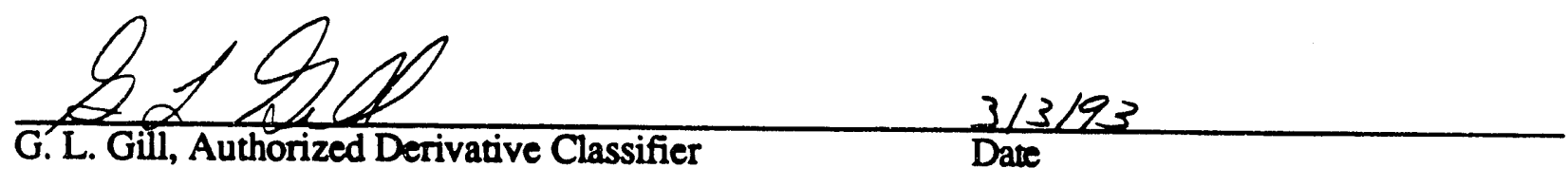

SRTC SAVANNAH RIVER TECHNOLOGY CENTER, AIKEN, SC 29808 Westinghouse Savannah River Company

Prepared for the U. S. Department of Energy under Contract DE-AC09-89SR18035 
PROJECT:

DOCUMENT: WSRC-TR-93-127

TITLE: $\quad$ ESTIMATE OF LOCA-FI PLENUM PRESSURE UNCERTAINTY FOR A FIVERING RELAP5 PRODUCTION REACTOR MODEL (U)

TASK: $\quad$ COMPUTATION OF REACTOR POWER LIMITS BY THE APPLIED REACTOR TECHNOLOGY GROUP

QA TASK NUMBER: 92-042.1

REVISION NUMBER: 0

APPROVALS

$\frac{B \text { Bume H. HARDY, TECHNTCAL REVIEWER }}{3 / 4 / 13}$

$\frac{\int D M \operatorname{lnm} a}{\text { J. D. MESIA, MANAGER, APPLIED REACTOR TECHNOLOGY }} \frac{3-4-93}{\text { DATE }}$

Q1 Glamete 3/5/93

A. J. GARRETT, MANAGER, NUCLEAR ENGINEERING DATE 
WSRC-TR-93-0127

\section{TABLE OF CONTENTS}

1.0 INTRODUCTIC N

2.01989 L REACTOR TEST SERIES AC4M

3.0 UNCERTAINTY ESTIMATION METHODOLOGY

4.0 UNCERTAINTY ESTIMATE RESULTS

5.0 CONCLUSIONS

6.0 REFERENCES

TABLES

FIGURES

APPENDIX A INTERP2 Program Listing

APPENDIX B "Interp.out" Files for AC4M Steps 19, 16, 27, 46, 14, 29, and 44

\section{LIST OF TABLES AND FIGURES}

Table 1

Table 2

Table 3

Table 4

Figure 1

Figure 2
Configurations of Selected AC4M Test Steps

Summary of INTERP2 Results for 7 AC4M Steps

Summary of Absolute Uncertainty Results for 7 AC4M Test Steps RELAP5 LOCA Plenum Pressures

1989 L Reactor Test Plenum Pressure Measurement Locations Five-Ring Plenuw Grid with TRAC Cell Numbering Convention 
WSRC-TR-93-0127

\section{ESTIMATE OF LOCA-EI PLENUM PRESSURE UNCERTAINTY FOR A} EIVE-RING RELAPS PRODUCTION REACTOR MODEL (U)

\section{INTRODUCTION}

The RELAP5/MOD2.5 code (RELAP5) ${ }^{1}$ is used to perform test-estimate analyses of certain postulated Design Basis Accidents (DBAs) in SRS production reactors. Currently, the most limiting DBA in terms of reactor power level is an instantaneous double-ended guillotine break (DEGB) loss of coolant accident (LOCA). A six-loop RELAP5 K Reactor model is used to analyze the reactor system behavior during the Flow Instability (FI) phase of the LOCA, which comprises only the first 5 seconds following the DEGB. 2 The RELAP5 K Reactor model includes tank and plenum nodalizations having five radial rings and six arimuthal sectors. ${ }^{3}$ The reactor system analysis provides time-dependent plenum and tank bottom pressures for use as boundary conditions in the FLOWTRAN code ${ }^{4}$, which models a single fuel assembly in detail. RELAP5 also performs the system analysis for the latter phase of the LOCA, denoted the Emergency Cooling System (ECS) phase. ${ }^{5}$ Results from the RELAP analysis are used to provide boundary conditions to the FLOWTRAN-TF code 6 , which is an advanced two-phase version of FLOWTRAN.

The RELAP5 K Reactor model has been tested for LOCA-FI 7 and Loss-of-Pumping Accident ${ }^{8}$ analyses and the results compared with equivalent analyses performed with the TRACPF1/MOD1 code 9 (TRAC). An equivalent RELAP5 six-loop, five-ring, six-sector L Reactor model has been benchmarked 3,10-12 against qualified single-phase system data from the 1989 L-Area In-Reactor Test Program 13,14. The RELAP5 K and L Reactor models have also been subjected to an independent Quality Assurance verification. 15

The quantification of uncertainty is an important element of determining safe operating power levels for SRS reactors. A detailed methodology for the determination of uncertainty for the FI phase of a DEGB LOCA has been developed. 16 In this methodology, uncertainties in the transient plenum and tank bottom pressures calculated by the reactor system code are two among many accounted for in determining the overall uncertainty in the nominal ("best estimate") power limits. Consequently, these system code uncertainties are quantified as part of the limits methodology. A methodology for estimating the uncertainty in the predicted timedependent plenum pressures for the DEGB LOCA was developed and applied originally to the TRAC code 17 In this methodology, the plenum pressure uncertainty is estimated by comparing steady-state plenum pressure data measured in L Reactor with TRAC benchmarks of the L Reactor tests, and confirmed by comparisons with RELAP5 LOCA results calculated by an independent group. A preliminary application of the plenum pressure uncertainty methodology to REILAPS has also been performed 18 . This report describes the application of a modified version of this methodology to the estimation of RELAP5 plenum pressure uncertainties for the FI phase of the LOCA.

\subsection{L REACTOR TEST SERIES AC4M}

As part of the effort to restart $P, K$, and $L$ Reactors following their shutdown in 1988, a series of tests were performed in L Reactor to provide integral hydraulic data pertinent to various modes of reactor operation. The tests were performed with a fresh Mark 22 charge at zero power. The reactor was operated with no helium cover gas and the blanket gas space vented to atmosphere. Many of these tests focused on the low tank level conditions characteristic of the 
ECS phase of a DEGB LOCA. In the these test series referred to as "AC4M," either 5 or 6 alternating current (AC) pump motors were used to drive the reactor coolant pumps during the tesis. The tank level was varied from overflow conditions to about 10" in successive hold points or "steps". Several of the steps conducted with the tank at overflow were selected for benchmarking the RELAP5 model and for estimating plenum pressure uncertainty. One of the selected test steps was performed with all six process pumps under both $\mathrm{AC}$ and direct current (DC) power as in normal operation. Three of the test steps were conducted with five process pumps under AC and DC power and the sixth pump inoperative. These three test steps resulted in backflow through the loop containing the inoperative pump, thereby simulating some of the thermal-hydraulic conditions expected in the LOCA. The remaining test steps were conducted with five process pumps under $A C$ and $D C$ power and the sixth pump inoperative with the loop rotovalves closed. This configuration produces a "no-flow" condition in one loop. Table 1 presents the basic configuration of the selected test steps.

One of the goals of the 1989 Tests was to measure the plenum pressure distribution in some detail. Special pressure tap plenum plugs were used to measure pressures inside the permanent sleeve and universal sleeve housing (USH) at approximately 30 plenum locations. 'The iocation of these pressure measurements on a reactor facemap is shown in Figure 1. As Figure 1 shows, each RELAP5 plenum cell encompasses all or part of a number (15-41) of permaneint sleeve positions. For the 1989 L Reactor tests, the 24 plenum cells comprising rings 1 through 4 ( 1 being the center ring) represent the region providing boundary conditions for the fuel assemblies. The positions associated with ring 5 are occupied by blanket assemblies, gas port sleeves, confinement heat removal instrument plugs, or long plenum plugs.

Figure 1 also shows that the pressure measurements were concentrated in the interior of the * plenum. At seven of these locations, flow down the assembly was blocked by additional instumentation packages. For these "no-flow" positions, the measured pressure is considered to be equal to the plenum pressure (i.e., the pressure outside the USH and permanent sleeve). For the remaining positions shown in Figure 1, the assembly was not blocked, so the measured pressure is less than the exterior plenum pressure because of the pressure drop associated with the flow through the slots in the permanent sleeve and the holes in the USH. The QUAL89 program 19 converts the pressure measurement made inside the permanent sleeve and USH to an average plenum pressure outside the permanent sleeve using data on pressure drop and flow rate measured in "A" tank. The methodology for this conversion was subjected to a technical review as part of the qualification effort for the $1985 \mathrm{~L}$ Reactor hydraulics data 20,21; the implementation of this methodology in QUAL89 has also been reviewed 22 . These converted plenum pressure measurements (referred to hereafter as "plenum data") have been used in the development and benchmarking of $L$ Reactor models for RELAP53,10-12 and are used in the current work as well.

\section{UNCERTAINTY ESTIMATION METHODOLOGY}

The details of the methodology and its prior application to the TRAC code are discussed in WSRC-TR-90-26317. The methodology for estimating the transient plenum pressure uncertainty was developed to be consistent with the uncertainty methodology itself. The uncertainty required for the limits analysis is for the time interval 0.5 to 2.0 seconds during the LOCA. It is given as one standard deviation of a normal distribution in terms of absolute pressure in pounds per square inch (psi). The plenum pressure uncertainty to be estimated is an average over the portion of the plenum that provides boundary conditions to flowzones $1-4$, since only these flowzones are considered in satisfying the core-wide probability of not exceeding the limits criterion. 
The plenum pressure uncertainty is estimated by comparing plenum pressure measurements from selected hold points, or "steps", from the AC4M test series run in L Reactor in 1989 to RELAP5 analyses of the tests. The RELAP5 code and a five-ring, six-sector 1989 L Reactor Test model were benchmarked against the seven AC4M steps by Gill 12 . The RELAP5 plenum pressure results from the benchmark analyses of the seven selected test steps are compared to the data using an approach consistent with the uncertainty methodology. The RELAP5 cellaveraged pressures are interpolated spatially to give calculated values at the location of each measured plenum pressure. The interpolation scheme, which uses a linear method in the azimuthal direction and a spline fit in the radial direction, is taken from the overall limits uncertainty methodology. As part of the preliminary estimation of RELAP5 plenum pressure uncertainty 18 , the INTERP1 program 17 used in the TRAC uncertainty analysis was modified to accept RELAP5 plenum pressure results in Pascals rather than psia and assembly azimuthal position in degrees rather than radians; some minor formatting changes were made as well. The resulting program, called INTERP 2 , is used to perform the comparison of calculated and measured plenum pressures. Appendix A contains a listing of INTERP2.

For a given test step, INTERP2 performs the interpolation of RELAP5 plenum pressures to the permanent sleeve locations where measurements were made and calculates the differences between the plenum pressure data and the interpolated RELAP5 pressures. Both absolute and relative pressure differences are calculated, as well as the sum and sum of the squares of the differences. The absolute difieiences are calculated as interpolated RELAP5 pressure minus measured pressure. The re iative differences are the absolute differences divided by the data.

The INTERP2 program is run for each test step in turn. Two input files are required for each run. The first file, "interp.in", contains the RELAP5 plenum pressures for the given test, the radii of the plenum rings, and the number of assembly positions to be compared. The 24 pressures for rings 1 through 4 are given in $\mathrm{Pascals}$ absolute $(\mathrm{Pa})$ and the radii in inches. The. calculated plenum pressures are ordered according to the TRAC plenum cell numbering convention shown in Figure 2. The second input file, "olcp.in", contains the On-Line Computer (OLC) number and "r, $\theta$ " location of each assembly position to be included and the corresponding measured plenum pressure, in psia. In this case, the 25 plenum pressure measurements corresponding to assembly positions in K-14.123 flowzones 1 through 4 are included. The radial positions are given in inches and the azimuthal positions given in degrees, with the azimuthal origin taken to be the radius between TRAC sectors 1 and 6 and increasing angles in the counterclockwise direction. The output of the INTERP2 program is written to a file called "interp.out". This file contains the RELAP5 plenum cell pressures, the plenum radii, and the total number of assembly positions considered. It also shows the interpolated REI_AP5 pressures, the pressure measurements, and the absolute and relative differences between them for each position considerer. Finally, the sum and sum of the squares of the differences (both absolute and relative) is given.

The sums and sums of squares of the pressure differences from INTERP2 are used to calculate the mean and standand deviation of all the differences for a number of tests. The mean and standard deviation of the distribution of the differences are calculated according to the following expressions:

$$
\begin{aligned}
& \mu=(\Sigma \delta) / N \\
& \sigma=\left\{\left[N \Sigma(\delta)^{2}-(\Sigma \delta)^{2}\right] /[N(N-1)]\right\}^{0.5}
\end{aligned}
$$

where, 
$\mu=$ the mean of the distribution of differences;

$\sigma=$ the standard deviation of the distribution of differences;

$\delta=$ the difference (absolute or relative) between the interpolated RELAP5 plenum

pressure and the measured plenum pressure at a particular location; and

$\mathrm{N}=$ the total number of pressure differences in the distribution.

This calculation is not done in INTERP2; rather it is done separately using the results from several INTERP2 runs. The derivation of Equation 2 is given in Ref. 17.

Once the mean and standard deviation of the sample distribution of differences are determined, they are used to estimate the plenum pressure uncertainty. The sample mean is an indication of any systematic difference, or bias, between the data and the irterpolated RELAP5 pressures. The sample standard deviation is a measure of the variability of the differences about the mean. The sample standard deviation obtained with Equation 2 can be used to make a conservative estimate of the transient uncertainty (given that any bias implied by the sample mean is also taken into account).

\subsection{UNCERTAINTY ESTIMATE RESULTS}

The INTERP2 program was run for the seven selected AC4M steps (i.e., 19, 16, 27, 46, 14, 29, and 44). Appendix B contains the "interp.out" files for the 7 steps (note that all the information from the "olcp.in" and "interp.in" files is also in the "interp.out" files).

Table 2 presents a summary of the INTERP2 results for the 7 steps. Each test had 25 measurements in positions corresponding to K-14.1 flowzones $1-4$, for a total of 175 comparisons. As discussed before, the values in Table 2 can be used to determine absolute and relative means and standard deviations for selected tests or groups of tests. In the previous uncertainty analyses 17,18 , the approach was to combine all the available tests to determine the plenum pressure error mean and standard deviation. For TRAC, the selected benchmark tests were either of the $6 \mathrm{AC}$ full flow or the $5 \mathrm{AC}$ with 1 backflow (BF) type. T. ough the " $5 \mathrm{AC}$, $1 \mathrm{BF}^{\prime \prime}$ tests provide flow and pressure distributions that are the most representative of a plenum inlet break LOCA, these tests alone were not considered to provide a complete basis for estimating plenum pressure uncertainty. The measurement positions in the $1985 \mathrm{~L}$ Reactor tests were concentrated in a $120^{\circ}$ sector, and in each case the backflow loops received flow from that sector. This distribution of measurement locations meant that plenum pressure behavior in regions receiving flow from loops with operating AC pumps was "underrepresented" in the "5 AC, 1 BF" type of test. Consequently, three "6 AC" tests were combined with three "5 AC, 1 BF" tests to provide a better representation of the plenum-wide pressure uncertainty.

In the preliminary estimate of RELAP5 plenum pressure uncertainty, the approach was to replicate the earlier TRAC methodology as much as possible. As Table 1 shows, the available qualified benchmark cases included three " 5 AC, 1 BF" but only one unique " 6 AC" case. The three tests of the $5 \mathrm{AC}$ with 1 no-flow (NF) type were included to increase the total number of tests (and data points) to be comparable to that used for TRAC.

As Figure 1 shows, the distribution of plenum pressure measurements in the $1989 \mathrm{~L}$ Reactor tests was not concentrated in any sector. There is therefore no apparent need to combine different types of tests as done previously. The three " 5 AC, 1 NF" tests provide information on the model's ability to predict another distinct type of plenum pressure distribution, but the 
applicability of these results to LOCA plenum pressure prediction uncertainty is somewhat indirect. The three "5 AC, 1 BF" tests alone may provide an appropriate and sufficient basis for the estimation of uncertainty. In order to decide the question of test selection, the three flow configurations represented in the tests are examined individually and then with all seven tests combined as before.

Table 3 shows the results of determining the means and standard deviations of the distributions of absolute plenum pressure prediction "errors" for the " $6 \mathrm{AC}$ " case, the three " $5 \mathrm{AC}, 1 \mathrm{NF}$ " cases, the three " $5 \mathrm{AC}, 1 \mathrm{BF}$ " cases, and all seven cases combined. The mean errors range from 0.35 psi for the " $5 \mathrm{AC}, 1 \mathrm{NF}$ " cases to 0.99 psi for the " $5 \mathrm{AC}, 1 \mathrm{BF}$ " cases. For all combinations, the mean is positive, indicating a positive plenum pressure "bias" in the RELAP5 model. The standard deviation ranges from 1.85 psi for the " $5 \mathrm{AC}, 1 \mathrm{NF}$ " cases to 2.34 psi for the " $6 \mathrm{AC}$ " case. Overall, the best benchmark results are for the " $5 \mathrm{AC}, 1 \mathrm{NF}$ " cases and the worst are for the " $5 \mathrm{AC}, 1 \mathrm{BF}$ " case. Note that the average plenum pressure is highest for the " $6 \mathrm{AC}$ " case and lowest for the " $5 \mathrm{AC}, 1 \mathrm{BF}$ " case. Thus, the amount of "error" in the prediction does not appear to be proportional to the average plenum pressure, but depends primarily on the configuration of the tests. In light of these results, it seems appropriate to base the uncertainty estimate upon the "5 AC, 1 BF" cases because they are the most "LOCA-like" and provide the most conservative estimate.

A second issue in arriving at a plenum pressure uncertainty estimate for the LOCA is the use of the absolute or relative mean and standard deviation from the data. One approach is to use the standard deviation in the absolute pressure differences as the basis for the uncertainty. Another approach is to use the standard deviation of relative differences as the measure of uncertainty and assume that the absolute uncertainty is proportional to the plenum pressure. This approach yields a lower uncertainty estimate for the LOCA because the pressure level during the LOCA is significantly lower than in the L Reactor tests.

The two approaches yield the following results:

Absolute pressure differences (interpolated RELAP5 minus data) -

$\begin{array}{ll}\text { mean: } & 0.99 \mathrm{psi} \\ \text { standard deviation: } & 2.05 \mathrm{psi}\end{array}$

Relative pressure differences (absolute differences divided by data) -

mean: $\quad 0.018$

standard deviation: $\quad \therefore \quad 0.033$

The average calculated LOCA plenum pressure in rings $1-3$ over the time period of interest is about 44 psia. Table 4 shows the RELAP5 plenum pressures in rings 1-3 at $0.5 \mathrm{~s}, 1.0 \mathrm{~s}, 1.5 \mathrm{~s}$, and 2.0 s during the $\mathrm{LOCA}^{7}$. The average of these pressures at each time is also shown.

Applying the relative mean of 0.018 and the relative standard deviation of 0.033 to the average plenum pressures (rings 1-3) at these times gives the following results:

time: $0.5 \mathrm{~s}$

time: $1.0 \mathrm{~s}$

time: $1.5 \mathrm{~s}$

time: $2.0 \mathrm{~s}$ mean: $0.80 \mathrm{psi}$

mean: $0.79 \mathrm{psi}$

mean: $0.78 \mathrm{psi}$

mean: $0.77 \mathrm{psi}$ standard deviation: $1.49 \mathrm{psi}$

standard deviation: $1.47 \mathrm{psi}$

standard deviation: $1.44 \mathrm{psi}$

standard deviation: $1.44 \mathrm{psi}$ 
Using this approach, the LOCA mean plenum pressure error and standard deviation over the time period of interest are approximately 0.8 psi and 1.5 psi, respectively, as compared to approximately $1.0 \mathrm{psi}$ and $2.1 \mathrm{psi}$, respectively, taken directly from the data. Since there is no basis in the data supporting the "scaling" of the uncertainty to the average plenum pressure, the higher values should be used. Historically, a transient plenum pressure uncertainty of $\pm 2.5 \mathrm{psi}$ with no bias correction has been used in determining the LDCA-FI effluent temperature limits. 16 Based upon the results given above, the LOCA-FI limits for K-15.1 should account for $\mathrm{a}+1.0 \mathrm{psi}$ bias in the predicted transient plenum pressures and retain the $\pm 2.5 \mathrm{psi}$ uncertainty used previously.

\subsection{CONCLUSIONS}

The transient plenum pressure uncertainty methodology used previously in the LOCA-FI limits methodology has been applied to the five-ring, six sector RELAP5 model that is the basis for the K-15.1 LOCA system analysis. Seven hold points from the 1989 L Reactor AC4M Test Series were evaluated as a basis for estimating the plenum pressure uncertainty. It was concluded that the uncertainty should be based upon the three data sets from simulated LOCA (5 loops under AC pumping with 1 loop in backflow) hold points. Measured plenum pressures from these tests were compared to calculated plenum pressures from RELAP5 benchmarks of the tests. The RELAPS pressures, which represent averages over relatively large plenum control volumes, were interpolated to give pressures at the locatinns where measurements were taken and a distribution of differences between measured and calculated pressures was obtained. The resulting distribution of differences have an absolute mean and standard deviation of 0.99 and 2.05 psi, respectively. The mean value of approximately 1.0 psi represents a "tias" in the RELAP5 prediction of plenum pressures that must be accounted for in the determination of effluent temperature limits. Therefore, it is recommended that the $\mathrm{K}-15.1$ LOCA-FI limits account for a $+1.0 \mathrm{psi}$ bias and a \pm 2.5 psi transient plenum pressure
uncertainty. 


\subsection{REFERENCES}

1. V. H. Ransom, et al., "RELAP5/MOD2 Code Manual Volurne 1: Code Structure, System Models, and Solution Methods," NUREG/CR-3412, U. S. Nuclear Regulatory Commission, EGG-2396, EG\&G Idaho, Inc., August 1985.

2. D. P. Griggs, "RELAP5 Predictions of K Reactor System Parameters for the Flow Instability Phase of a Plenum Inlet DEGB LOCA (U)," WSRC-TR-93-0091, February 1993.

3. G. L. Gill, interoffice memorandum, RELAP5/MOD2.5 5-Ring Tank Model Development and Benchmarking, NES-ART-920332, October 5, 1992.

4. S. E. Aleman, et al., "FLOWTRAN: An Algorithm for Describing the Thermal-Hydraulic Behavior of SRP Assemblies," DPSTM-140, September 1989.

5. "RELAP5 Calculations of a Savannah River Reactor Large Break Loss-cf-Coolant Accident," ERA-NRE-xx-93, EG\&G Idaho, Inc., draft report of February 1993.

6. G. P. Flach, et al., "FLOWTRAN-TF Code Description," WSRC-TR-90-413, December 1990.

7. D. P. Griggs, interoffice memorandum, Comparison of TRAC and RELAP5 Predictions of KReactor System Parameters for Steady-State and DEGB LOCA Conditions, NES-ART920337, October 13, 1992.

8. J. R. Larson, "Comparison of RELAP5 and TRAC Results for a Loss-of-Pumping Accident," EGG-NE-10527, EG\&G Idaho, Inc., October 1992.

9. Safety Code Development Group "TRAC-PF1/MOD1: An Advanced Best-Estimate Computer Program for Pressurized Water Reactor Thermal-Hydraulic Analysis," Los Alamos National Laboratory report LA-10157-MS (NUREG/CR-3858), July 1986.

10. P. K. Paul, interoffice memorandum, Benchmarking RELAP5MOD2.5 5-Ri1g Model with Tank Overflow LOPA Tests, NES-ART-920335, October 9, 1992.

11. D. T. Herman, interoffice memorandum, RELAP5 Benchmark Calculation of $1989 \mathrm{~L}$ Area Test DC-9 Steps 3, 10 and 12 for TRAC-to-RELAP Conversion, NES-ART-920340, October 6, 1992.

12. G. L. Gill, "RELAP5 Results Comparison with 1989 L-Area Test Data for Use in LOCAFI and LOPA Uncertainty Analyses," WSRC-TR-93-0082, February 1993.

13. L. D. Goodrich, TRANSMUUAL OF QUALIFIED DATA, Idaho National Engineering Laboratory, letter to J. C. Whitehouse, July 24, 1992.

14. J. C. Whitehouse, interoffice memorandum, L-Area Phase 1 Qualified Data Transmittal, Tests DC9. AC6. AC10, and AC4M, NES-ETH-920363, October 20, 1993.

15. M. J. Gaeta, Results of Quality Assurance Task, EG\&G Idaho Letter, MJG-5-92, October 9, 1992.

16. B. J. Hardy and A. M. White, "A Probabilistic Method for Determining Effluent Temperature Limits for Flow Instability for SRS Reactors," WSRC-TM-90-5 (DPSTM-160), June 1990. 
17. D. P. Griggs, "Uncertainties in TRAC Plenum Pressures for the FI Phase of a DEGB LOCA," WSRC-TR-90-263, May 1991.

:8. D. P. Griggs, interoffice memorandum, Preliminary Estimate of Plenum Pressure Uncernainty for a Five-Ring RELAPS Production Reactor Model, NES-ART-920350, October 14, 1992.

19. L. D. Koffman, interoffice memorandum, QUAL 89: A Program Summary and Processing of Data Files, NES-CDG-910235, November 20, 1991.

20. T. B. Edwards, et al., 'Data Qualification Summary for 1985 L-Area AC Flow Tests," IVSRC-TR-92-134.

21. M. L. Liebmann, interoffice memorandum, Technical Review of ACDATA2 \& PLENUM Brograms, NES-ART-910216, July 25, 1991.

22. C. P. May, interoffice memorandum. OUAL89 PLENUM routine review. Task \# 92-0431, NES-HTL-93-0028, February 12, 1993.

23. R. F. Swingle, "K-14.1 Mark 22 Charge Flow Design Revision 1," RTM-5036, Rev. 1, WSRC-TR-90-00218, June 1990. 
WSRC-TR-93-0127

Table 1

Configurations of Selected AC4M Test Steps

\begin{tabular}{ccllccccr}
\multicolumn{3}{c}{ Tank } & \multicolumn{7}{c}{ Process Water Systems } \\
Step & Level (in) & Pumps & 1 & 2 & 3 & 4 & 5 & 6 \\
\hline 19 & 229.9 & 6 AC & AC & AC & AC & AC & AC & AC \\
16 & 228.7 & 5 AC & AC & BF & AC & AC & AC & AC \\
27 & 228.5 & 5 AC & AC & AC & BF & AC & AC & AC \\
46 & 228.8 & 5 AC & AC & AC & AC & BF & AC & AC \\
14 & 229.6 & 5 AC & AC & NF & AC & AC & AC & AC \\
29 & 229.5 & 5 AC & AC & AC & NF & AC & AC & AC \\
44 & 229.6 & 5 AC & AC & AC & AC & NF & AC & AC
\end{tabular}

Key: AC - pumps operated with AC and DC motors, normal full flow in system;

BF - pump off, backflow in system;

NF - pump off, rotovalves closed, no flow in system.

TABLE 2

SUMMARY OF INTERP2 RESULTS FOR 7 AC4M TEST STEPS

\begin{tabular}{|c|c|c|c|c|c|}
\hline Step & $N$ & \multicolumn{2}{|c|}{ Absolute Differences } & \multicolumn{2}{c|}{ Relative Differences } \\
\cline { 3 - 6 } & & $\Sigma \delta$ & $\Sigma\left(\delta^{2}\right)$ & $\Sigma \delta$ & $\Sigma\left(\delta^{2}\right)$ \\
\hline 19 & 25 & 15.65 & 141.38 & 0.209 & 0.021 \\
\hline 16 & 25 & 21.10 & 132.99 & 0.551 & 0.037 \\
\hline 27 & 25 & 28.35 & 146.47 & 0.517 & 0.042 \\
\hline 46 & 25 & 14.76 & 104.12 & 0.277 & 0.027 \\
\hline 14 & 25 & 18.46 & 94.03 & 0.296 & 0.021 \\
\hline 29 & 25 & 5.37 & 85.88 & 0.101 & 0.019 \\
\hline 44 & 25 & 2.21 & 81.63 & 0.052 & 0.017 \\
\hline Total & 175 & 115.90 & 786.50 & 2.003 & 0.184 \\
\hline
\end{tabular}


TABLE 3

SUMMARY OF ABSOLUTE UNCERTAINTY RESULTS FOR 7 AC4M TEST STEPS

\begin{tabular}{|l|l|c|c|c|c|}
\hline Step & $\mathrm{N}$ & \multicolumn{2}{|c|}{ Absolute Differences } & mean & Sigma \\
\hline & & $\Sigma \delta$ & $\Sigma\left(\delta^{2}\right)$ & Dsi & DSi \\
\hline $6 \mathrm{AC}$ & 25 & 15.65 & 141.38 & 0.63 & 2.34 \\
\hline $\mathrm{SAC} \cdot 1 \mathrm{NF}$ & 75 & 26.04 & 261.54 & 0.35 & 1.85 \\
\hline $\mathrm{SAC} \cdot \mathrm{BE}$ & 75 & 74.21 & 383.58 & 0.99 & 2.05 \\
\hline All seven & 175 & 115.90 & 786.50 & 0.66 & 2.02 \\
\hline
\end{tabular}

TABLE 4

RELAP5 LOCA PLENUM PRESSURES

\begin{tabular}{|l|c|c|c|c|}
\hline \multicolumn{1}{|c|}{$\begin{array}{c}\text { RELAPS Plenum } \\
\text { Cell }\end{array}$} & \multicolumn{4}{|c|}{ Plenum Pressure (kPa) at: } \\
\cline { 2 - 5 } Ring 1, Sector 1 (3) & 299.27 & 294.38 & 286.87 & $2.0 \mathrm{~s}$ \\
Ring 1, Sector 2 & 299.84 & 294.96 & 287.44 & 287.87 \\
Ring 1, Sector 5 & 286.06 & 281.44 & 274.25 & 274.25 \\
Ring 1, Sector 6 (4) & 294.36 & 289.53 & 282.13 & 282.13 \\
Ring 2, Sector 1 (3) & 319.27 & 314.62 & 306.98 & 306.98 \\
Ring 2, Sector 2 & 320.60 & 315.98 & 309.93 & 308.33 \\
Ring 2, Sector 5 & 275.19 & 271.35 & 266.06 & 264.70 \\
Ring 2, Sector 6 (4) & 307.26 & 302.61 & 296.73 & 295.17 \\
Ring 3, Sector 1 (3) & 340.44 & 336.18 & 330.11 & 328.44 \\
Ring 3, Sector 2 & 342.28 & 338.05 & 331.98 & 330.31 \\
Ring 3, Sector 5 & 270.35 & 266.99 & 261.97 & 260.66 \\
Ring 3. Sector 6(4) & 323.65 & 319.26 & 313.36 & 311.74 \\
\hline \multicolumn{1}{|c|}{ Average, kPa } & 308.94 & 304.55 & 298.68 & 297.13 \\
Average, psia & 44.81 & 44.17 & 43.32 & 43.10 \\
\hline
\end{tabular}


Figure 1

1989 L Reactor Test Plenum Pressure Measurement Locations

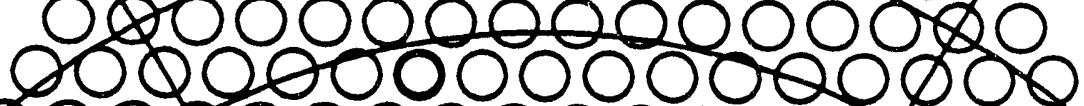

(a)

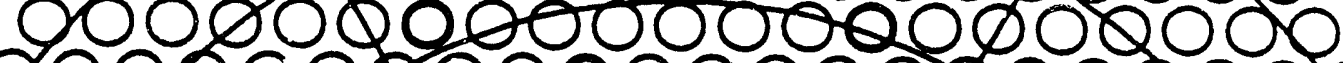

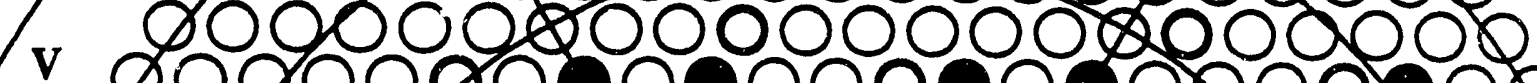

L

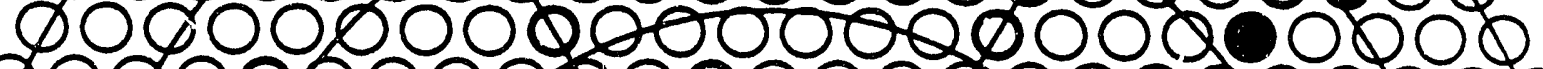

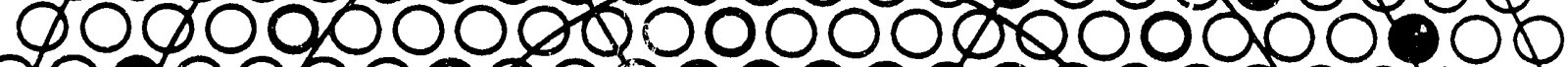

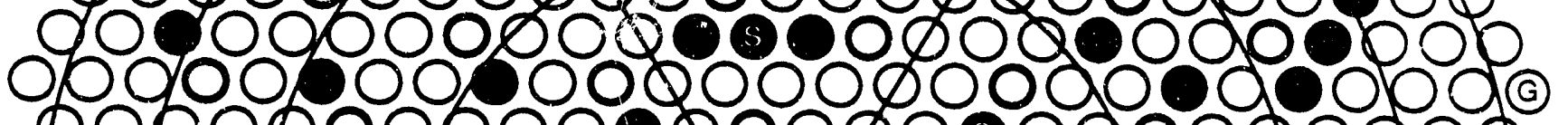

Dopoloopoogooposodoododod

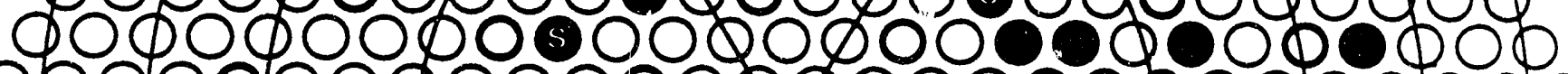

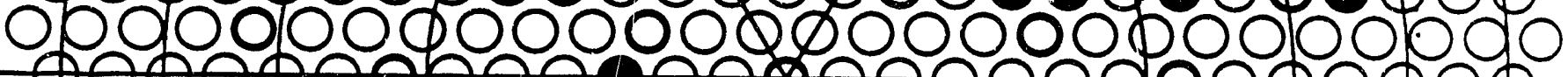

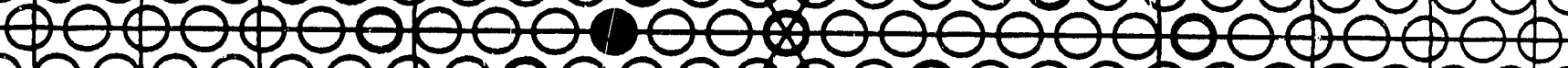

Opoloopoooopq0000010000000

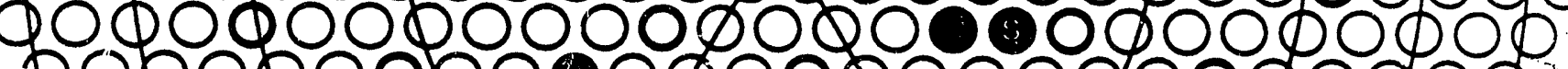

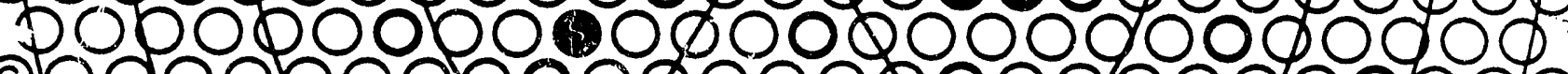

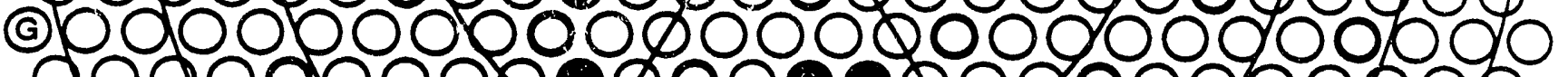

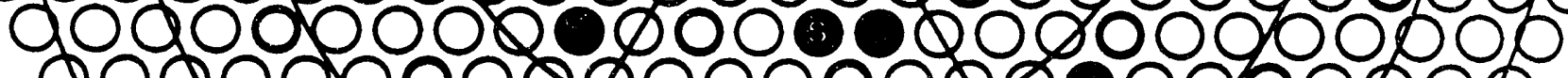

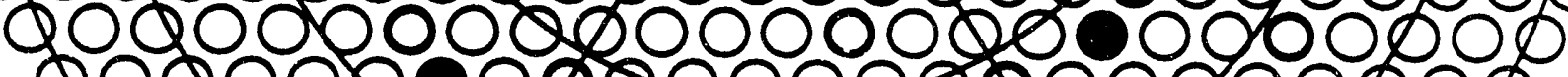

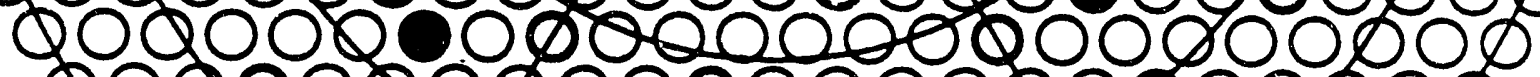

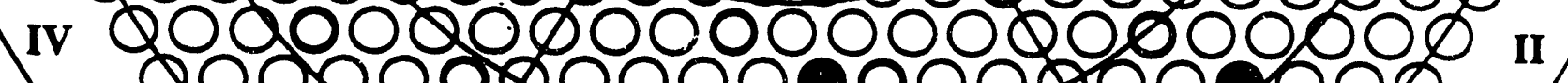
goopoopo000000\$00

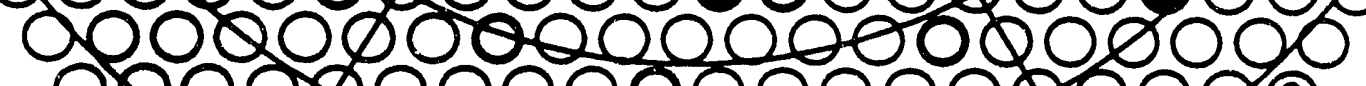

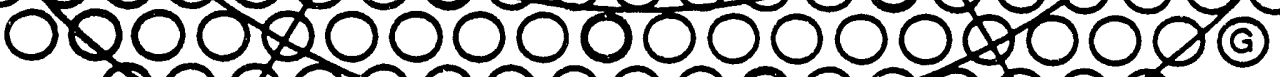

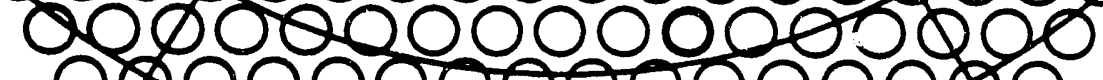

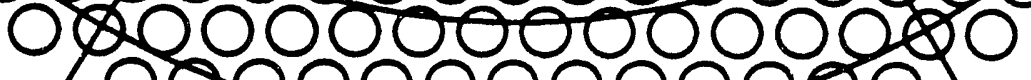

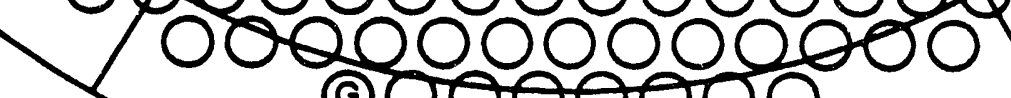

(a) 000000

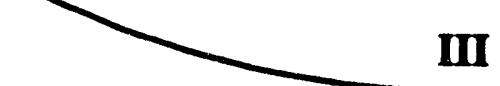


WSRC-TR-93-0127

Figure 2

Five-Ring Plenum Grid with TRAC Cell Numbering Convention Roman Numerals Indicate SRS Process Water System Numbers

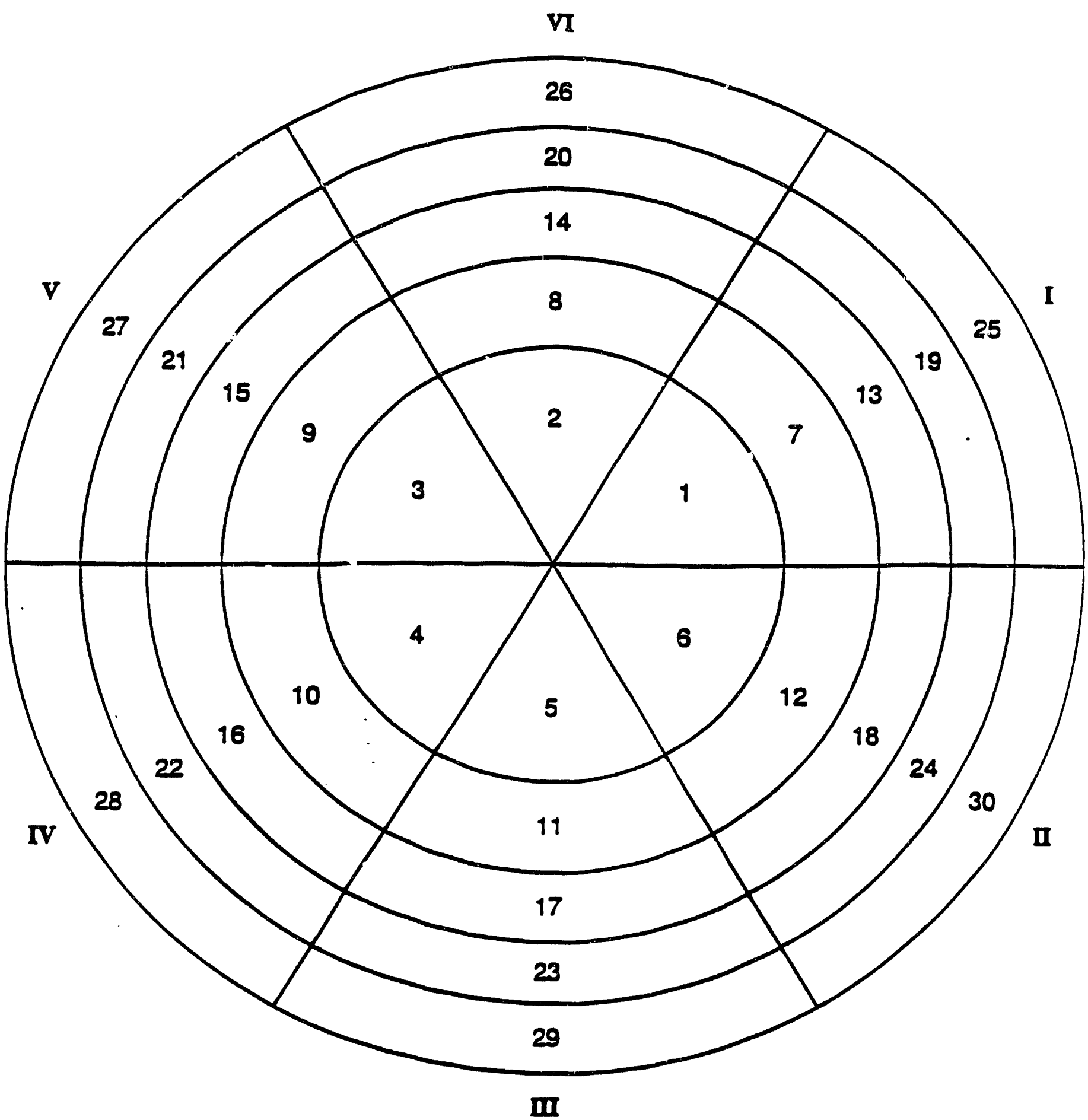


WSRC-TR-93-0127

APPENDIX A

INTERP2 Program Listing 


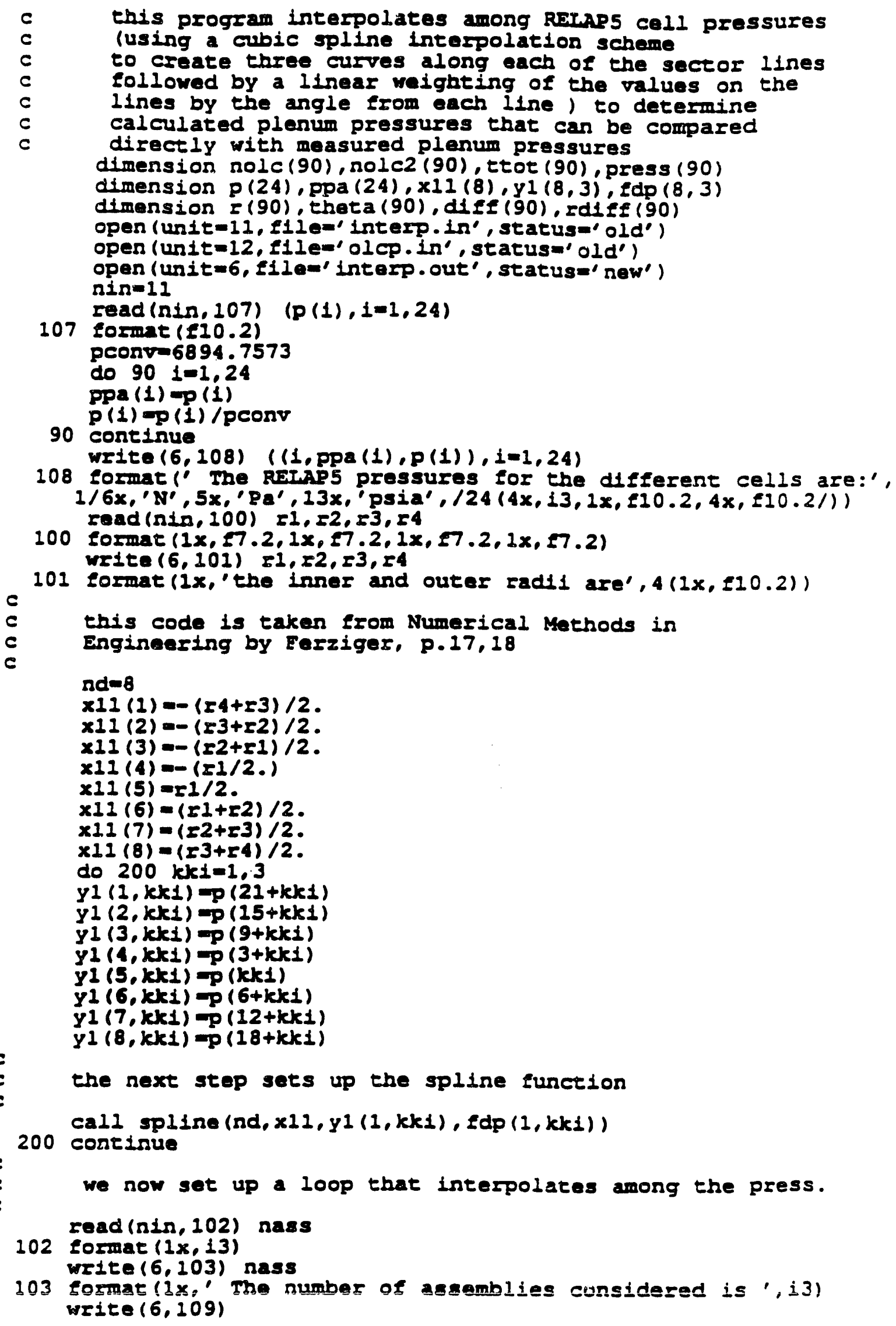




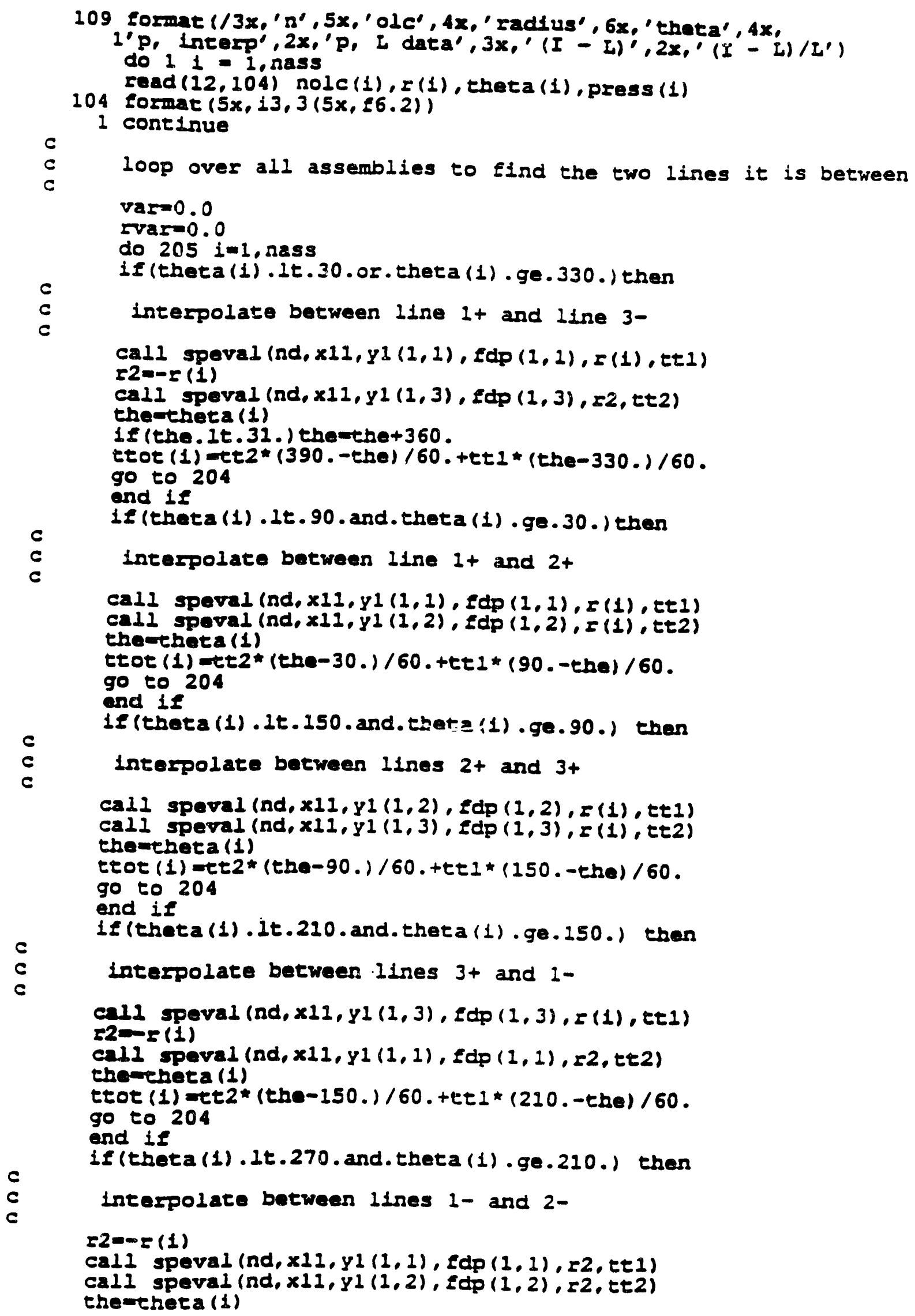


WSRC-TR-93-0127

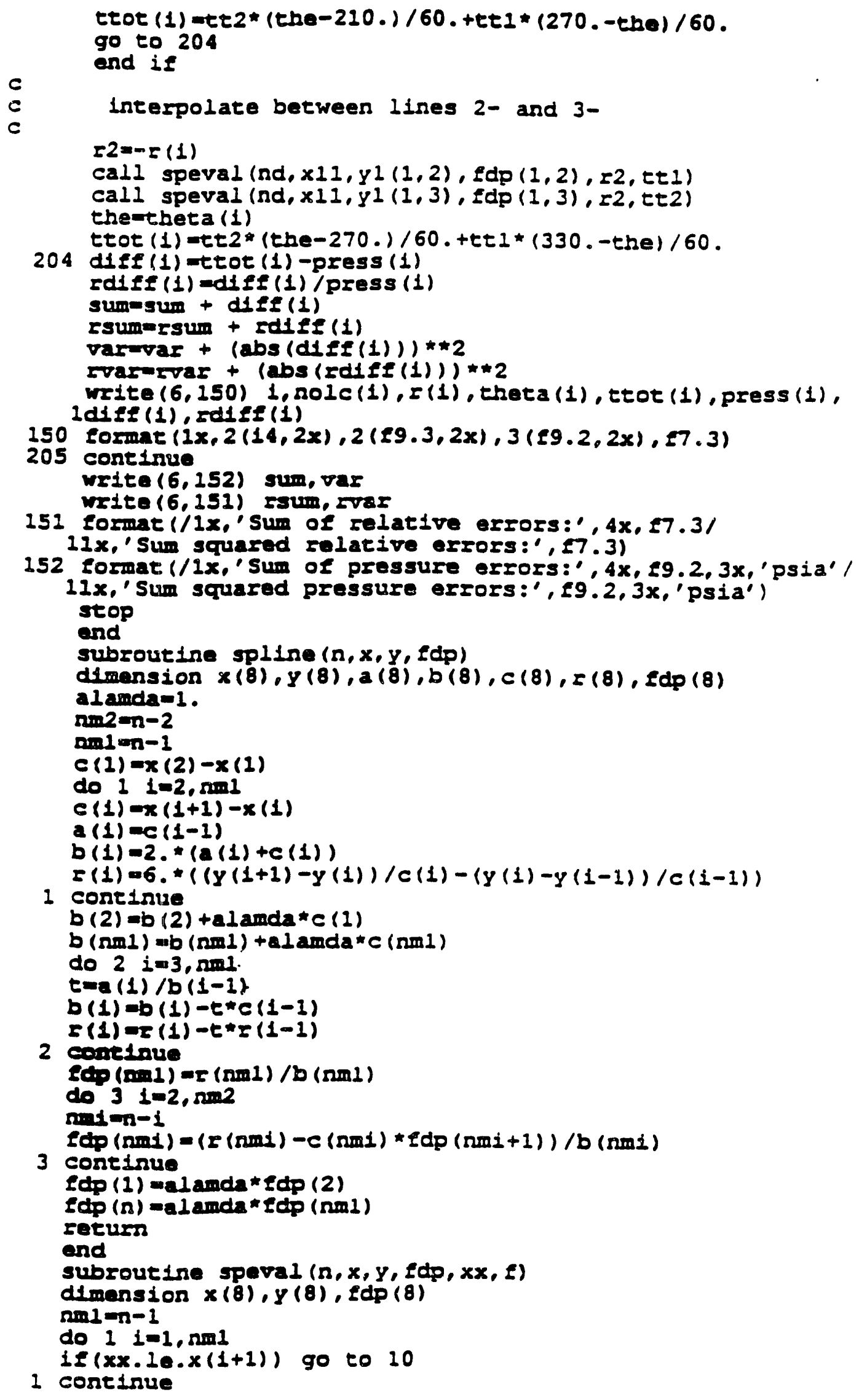


WSRC-TR-93-0127

$10 \operatorname{dran} x x-x(1)$

$d x p=x(1+1)-x x$

del $=x(1+1)-x(1)$

$f=f d p(1) * d x p *(d x p * * 2 / d e 1-d e 1) / 6,+f d p(1+1) * d x=(d x m * * 2 / d e 1-$ ldel) $/ 6 .+y(1) \star d x p / d e l+y(1+1) * d x$ m $/$ del

гeturs

end 
WSRC-TR-93-0127

\section{APPENDIX B}

"Interp.out" Files for AC4M Steps 19,16,27,46,14,29, and 44 
WSRC-TR-93-0127

\section{"Interp.out" File for AC4M Step 19}

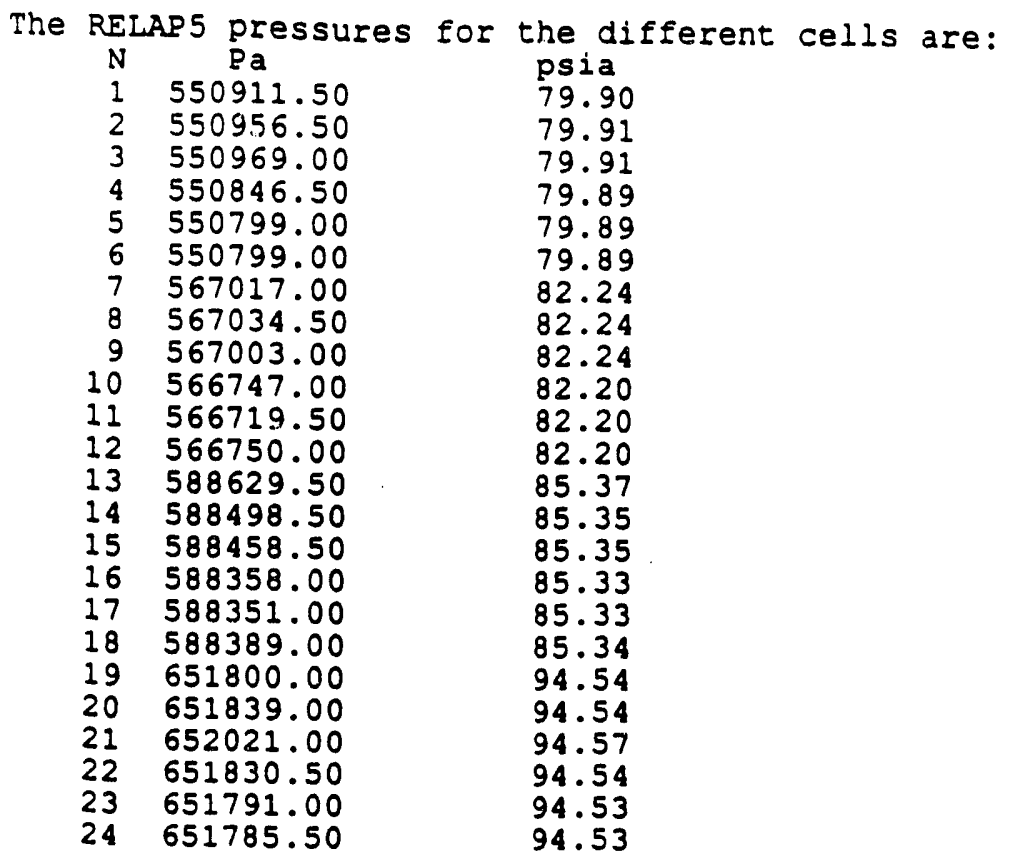

the inner and outer radii are

n olc radius theta

198 61.020

$201 \quad 42.580$

$100 \quad 25.240$

$54 \quad 37.040$

$127 \quad 54.670$

24273.080

$59 \quad 30.510$

$115 \quad 56.000$

$124 \quad 49.000$

$129 \quad 50.480$

$238 \quad 67.510$

$243 \quad 67.510$

$248 \quad 71.040$

1524.250

$148 \quad 50.480$

7132.080

$161 \quad 54.670$

$83 \quad 38.970$

177

34

57.300

21.000

30.510

32.080

106

110

210

50.480

56.000

50.480
156.590

145.280

133.900

19.110

26.330

24.500

23.410

60.000

38.210

13.900

38.950

21.050

9.830

330.000

313.900

289.110

273.670

231.050

227.780

180.000

83.410

109.110

73.900

120.000

106.100 $p$, interp 82.91 81.29

80.06

80.84

82.28

86.51

80.38

82.39

81.81

81.92

84.28

84.28

85.55

79.98

81.89

80.46

82.24

80.97

82.46

79.83

80.39

80.50

81.94

82.39

81.94

63.47

90.39

P. I data

87.73

81.12

80.59

80.73

82.91

89.15

80.71

85.02

79.36

79.17

83.13

80.36

79.67

80.74

81.31

79.93

82.05

79.75

78.97

80.96

80.62

79.22

82.37

78.29

80.01

psia

Sum of pressure errors:

15.65

psia

Sum of relative errors:

0.209

Sum squared relative errors: 0.021

$$
\begin{array}{rr}
(I-I) & (I-L) / L \\
-4.82 & -0.055 \\
0.17 & 0.002 \\
-0.53 & -0.007 \\
0.11 & 0.001 \\
-0.63 & -0.008 \\
-2.64 & -0.030 \\
-0.33 & -0.004 \\
-2.63 & -0.031 \\
2.45 & 0.031 \\
2.75 & 0.035 \\
1.15 & 0.014 \\
3.92 & 0.049 \\
5.88 & 0.074 \\
-0.76 & -0.009 \\
0.58 & 0.007 \\
0.53 & 0.007 \\
0.19 & 0.002 \\
1.22 & 0.015 \\
3.49 & 0.044 \\
-1.13 & -0.014 \\
-0.23 & -0.003 \\
1.28 & 0.016 \\
-0.43 & -0.005 \\
4.10 & 0.052 \\
1.93 & 0.024
\end{array}
$$




\section{"Interp.out" File for AC4M Step 16}

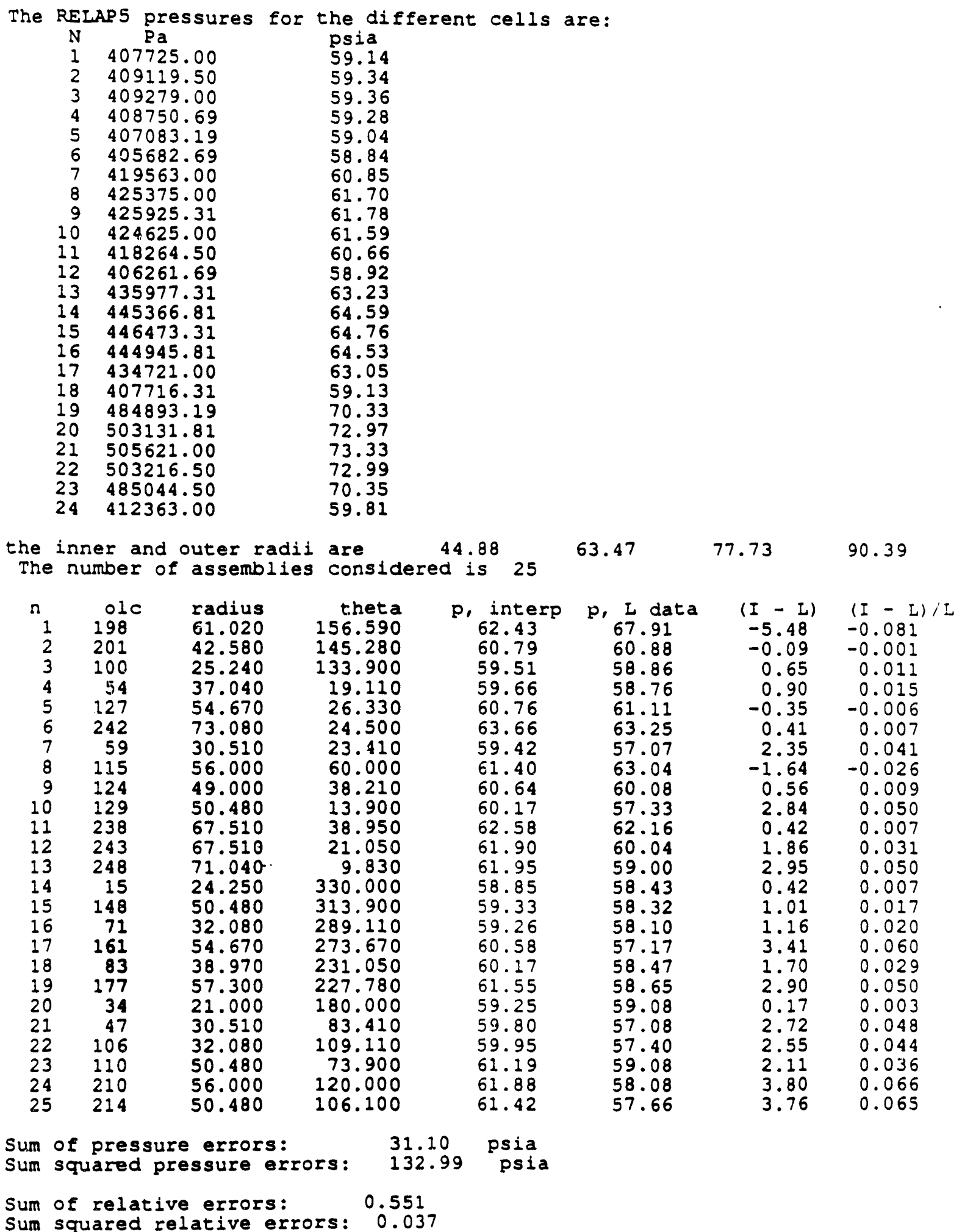


WSRC-TR-93-0127

\section{"Interp.out" File for AC4M Step 27}

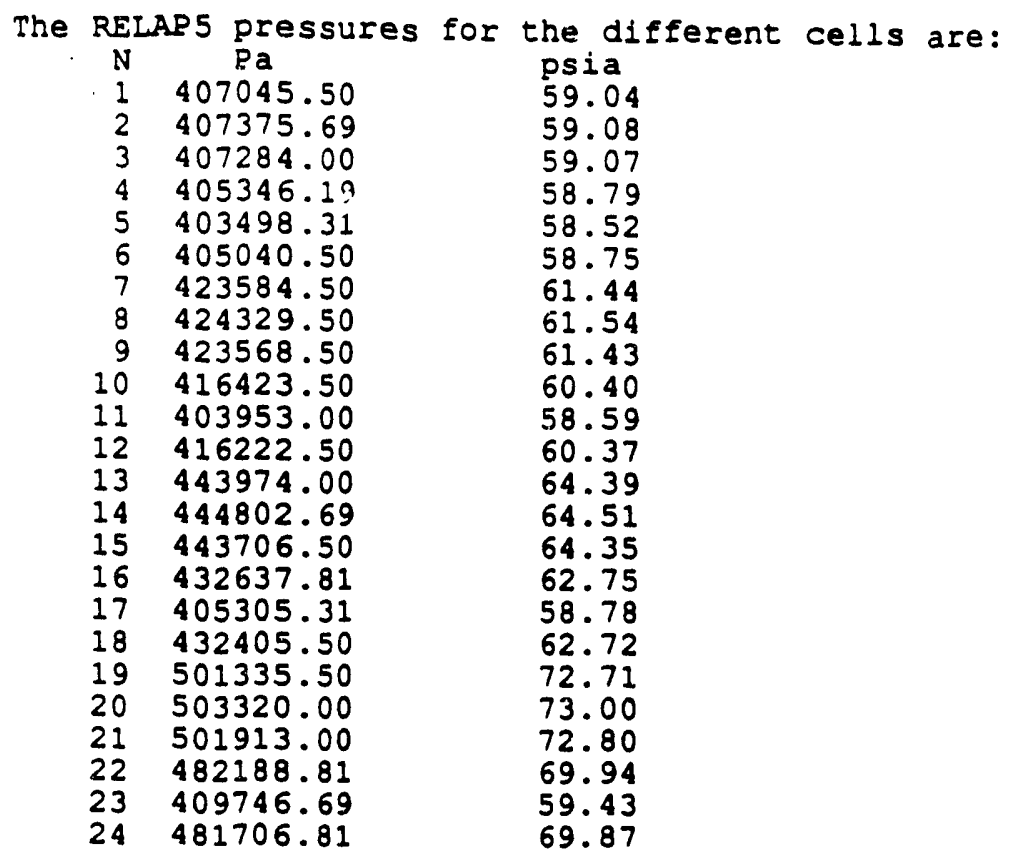

The number of assemblies considered is 25

$\begin{array}{rrr}n & \text { olc } & \text { radius } \\ 1 & 198 & 61.020 \\ 2 & 201 & 42.580 \\ 3 & 100 & 25.240 \\ 4 & 54 & 37.040 \\ 5 & 127 & 54.670 \\ 6 & 242 & 73.080 \\ 7 & 59 & 30.510 \\ 8 & 115 & 56.000 \\ 9 & 124 & 49.000 \\ 10 & 129 & 50.480 \\ 11 & 238 & 67.510 \\ 12 & 243 & 67.510 \\ 13 & 248 & 71.040 \\ 14 & 15 & 24.250 \\ 15 & 148 & 50.480 \\ 16 & 71 & 32.080 \\ 17 & 161 & 54.670 \\ 18 & 83 & 38.970 \\ 19 & 177 & 57.300 \\ 20 & 34 & 21.000 \\ 21 & 47 & 30.510 \\ 22 & 106 & 32.080 \\ 23 & 110 & 50.480 \\ 24 & 210 & 56.000 \\ 25 & 214 & 50.480\end{array}$

theta
156.590
145.280
133.900
19.110
26.330
24.500
23.410
60.000
38.210
13.900
38.950
21.050
9.830
330.000
313.900
289.110
273.670
231.050
227.780
180.000
83.410
109.110
73.900
120.000
106.100

p, interp 61.96

60.49

59.23

59.90

61.41

65.27

59.48

61.64

61.01

60.86

63.41

63.17

63.99

58.81

59.73

58.74

58.70

59.20

60.00

58.87

59.58

59.69

61.20

61.64

63.47

77.73

90.39

sum of pressure errors:

61.20

p, I data

65.21

58.97

58.12

59.59

62.79

68.18

58.50

64.99

60.03

58.74

63.74

61.69

60.05

56.78

55.02

57.55

57.30

55.95

57.39

56.85

58.69

56.62

62.09

57.56

58.45

$$
\begin{array}{r}
(I-L) \\
-3.25 \\
1.52 \\
1.11 \\
0.31 \\
-1.38 \\
-2.91 \\
0.98 \\
-3.35 \\
0.98 \\
2.12 \\
-0.33 \\
1.48 \\
3.94 \\
2.03 \\
4.71 \\
1.19 \\
1.40 \\
3.25 \\
2.61 \\
2.02 \\
0.89 \\
3.07 \\
-0.89 \\
4.08 \\
2.75
\end{array}
$$

2.75

$(I-L) / 5$

$-0.050$

0.026

0.019

0.005

$-0.022$

$-0.043$

0.017

$-0.051$

0.016

0.036

$-0.005$

0.024

0.066

0.036

0.086

0.021

0.024

0.058

0.045

0.036

0.015

0.054

$-0.014$

0.071

$$
\begin{array}{lll}
\text { Sum of pressure errors: } & 28.35 & \text { psia } \\
\text { Sum squared pressure errors: } & 146.47 & \text { psia }
\end{array}
$$

Sum of relative errors:

0.517

sum squared relative errors: 0.042 
WSRC-TR-93-0127

\section{"Interp.out" File for AC4M Step 46}

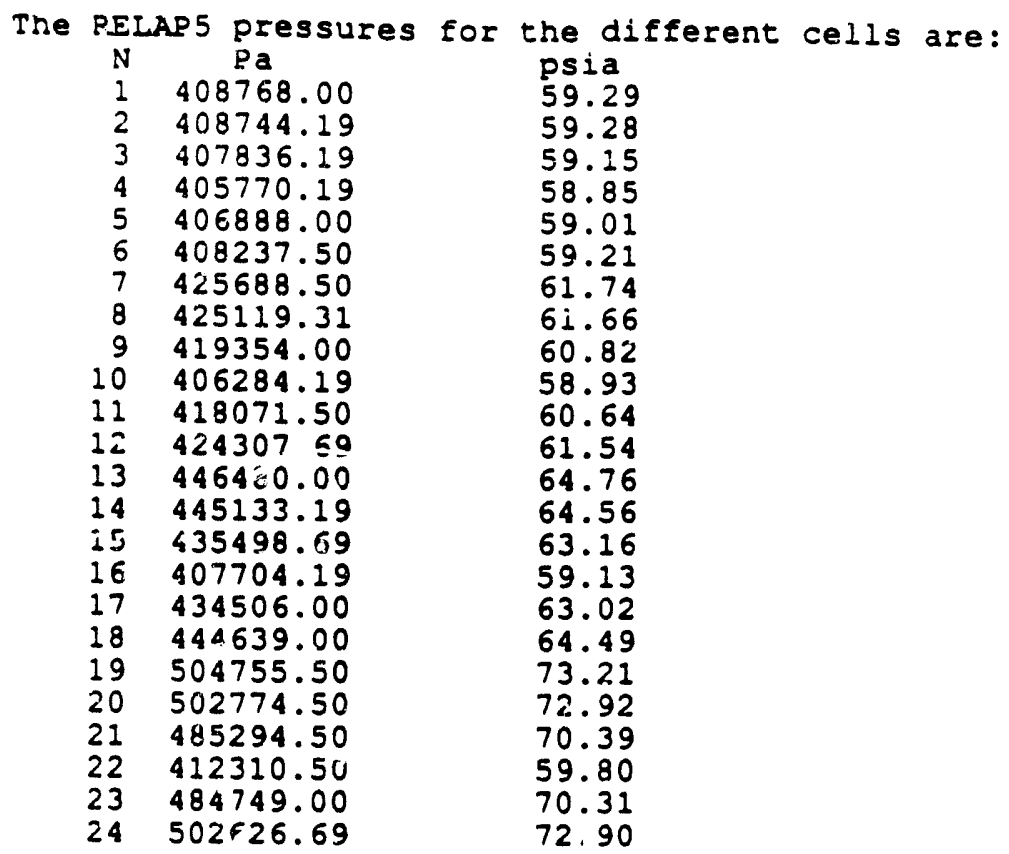

the inner and outer radii are 44.88
The number of asgemblies considered is 25

$\begin{array}{rrr}r & \text { olc } & \text { radius } \\ 1 & 198 & 61.020 \\ 2 & 201 & 42.580 \\ 3 & 100 & 25.240 \\ 4 & 54 & 37.040 \\ 5 & 127 & 54.670 \\ 6 & 242 & 73.080 \\ 7 & 59 & 30.510 \\ 8 & 115 & 56.600 \\ 9 & 124 & 49.000 \\ 10 & 129 & 50.480 \\ 11 & 238 & 67.510 \\ 12 & 243 & 67.510 \\ 13 & 248 & 71.040 \\ 14 & 15 & 24.250 \\ 15 & 148 & 50.480 \\ 16 & 71 & 32.080 \\ 17 & 161 & 54.670 \\ 18 & 83 & 38.970 \\ 19 & 177 & 57.300 \\ 20 & 34 & 21.000 \\ 21 & 47 & 30.510 \\ 22 & 106 & 32.080 \\ 23 & 110 & 50.480 \\ 24 & 210 & 56.000 \\ 25 & 214 & 50.480\end{array}$

theta
156.590
145.280
133.500
19.110
26.330
24.500
23.410
60.000
38.210
13.900
38.950
21.050
9.830
330.000
313.900
289.110
273.670
231.050
227.780
180.000
83.410
109.110
73.900
120.000
106.100

p, interp 61.05 60.20

59.31

60.24

61.77

65.79

59.76

61.85

61.28

61.37

63.71

63.70

64.84

59.30

$5: .32$

53.54

60.72

59.21

59.50

58.97

59.78

59.80

61.37

61.37

53.47

77.73

$90.3 \%$

14.76

61.16

p. I data

$(I-L)$

$(I-L) / 2$

58.84

58.83

60.10

63.58

70.39

58.94

66.08

59.77

59.35

64.38

62.47

61.83

57.99

58.73

56.16

59.64

58.26

58.20

58.51

59.68

58.03

63.42

58.28

59.59

$$
\begin{array}{r}
0.24 \\
1.35 \\
0.48 \\
0.14 \\
-1.81 \\
-4.60 \\
0.82 \\
-4.23 \\
1.51 \\
2.02 \\
-0.67 \\
1.23 \\
3.01 \\
1.31 \\
2.29 \\
1.38 \\
1.08 \\
0.95 \\
1.30 \\
0.46 \\
0.10 \\
1.77 \\
-2.05 \\
3.09 \\
1.57
\end{array}
$$

0.004

0.023

0.008

$-0.028$

$-0.065$

$-0.064$

.025

0.034

$-0.010$

0.049

0.023

0.039

0.018

0.016

0.022

0.008

0.030

$-0.032$

0.053

0.026

Sum of relative errors:

104.12

sum squared relative errors: 0.027 
WSRC-TR-93-0127

\section{"Interp.out" File for AC4M Step 14}

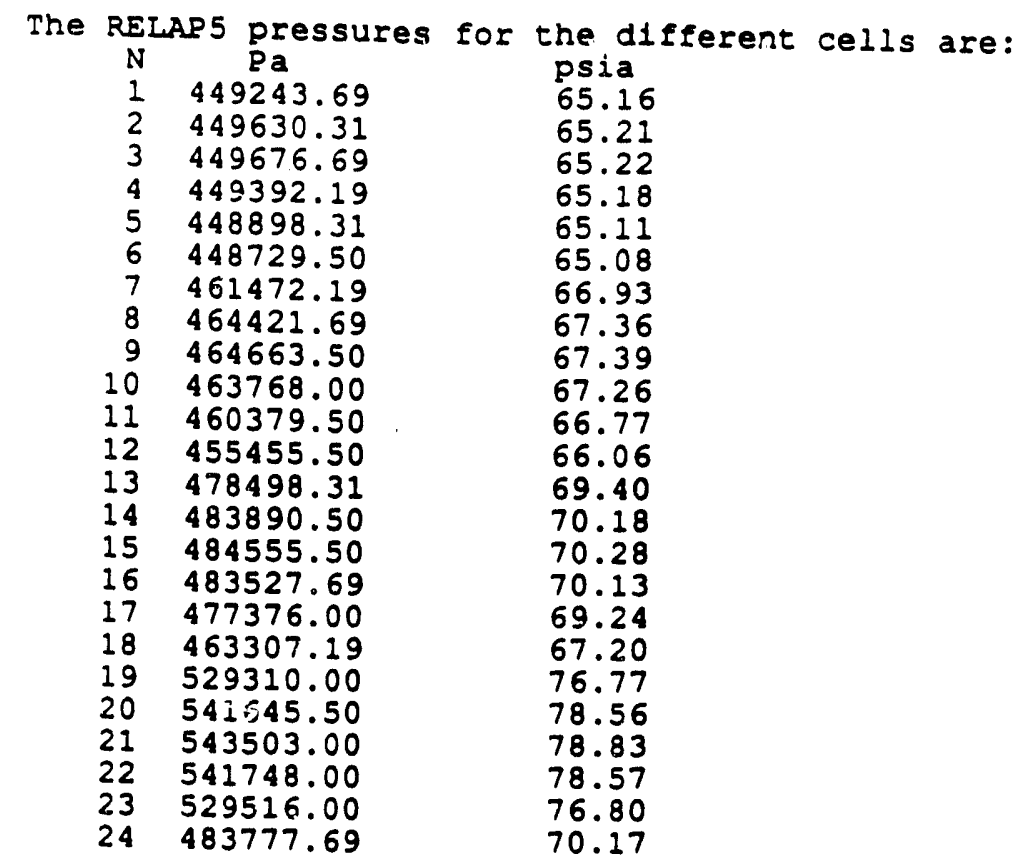

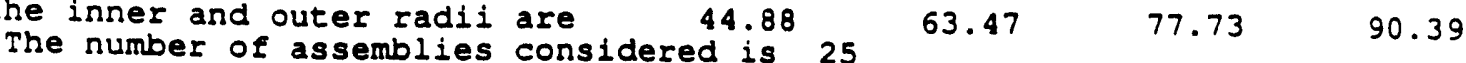

$\begin{array}{rrr}n & \text { olc } & \text { radius } \\ 1 & 198 & 61.020 \\ 2 & 201 & 42.580 \\ 3 & 100 & 25.240 \\ 4 & 54 & 37.040 \\ 5 & 127 & 54.670 \\ 6 & 242 & 73.080 \\ 7 & 59 & 30.510 \\ 8 & 115 & 56.000 \\ 9 & 124 & 49.000 \\ 10 & 129 & 50.480 \\ 11 & 238 & 67.510 \\ 12 & 243 & 67.510 \\ 13 & 248 & 71.040 \\ 14 & 15 & 24.250 \\ 15 & 148 & 50.480 \\ 16 & 71 & 32.080 \\ 17 & 161 & 54.670 \\ 18 & 83 & 38.970 \\ 19 & 177 & 57.300 \\ 20 & 34 & 21.000 \\ 21 & 47 & 30.510 \\ 22 & 106 & 32.080 \\ 23 & 110 & 50.480 \\ 24 & 210 & 56.000 \\ 25 & 214 & 50.480\end{array}$

theta
156.590
145.280
133.900
19.110
26.330
24.500
23.410
60.000
38.210
13.900
38.950
21.050
9.830
330.000
313.900
289.110
273.670
231.050
227.780
180.000
83.410
109.110
73.900
120.000
106.100

p, interp 68.01

66.50

65.36

65.81

66.91

70.06

65.50

67.27

66.66

66.49

68.63

68.28

68.78

65.13

66.10

65.47

66.76

66.06

67.35

65.14

65.64

65.76

66.98

67.51

67.09

p. I data

73.16

$(I-L)$

$(I-I) / I$

66.52

65.47

65.67

67.24

69.85

$-5.15$

$-0.02$

$-0.11$

0.14

$-0.33$

0.21

65.20

69.20

66.14

64.92

67.54

66.16

64.87

65.64

65.60

64.48

65.30

64.72

64.64

65.61

64.64

64.63

65.69

63.78

64.10

0.30

$-1.93$

0.52

1.57

1.09

2.12

$-0.070$

0.000

$-0.002$

0.002

$-0.005$

0.003

0.005

$-0.028$

0.008

0.024

0.016

3.91

0.032

$-0.51$

0.50

0.060

$-0.008$

0.99

0.008

1.46

0.015

0.022

1.34

0.021

0.042

$-0.47$

$-0.007$

$1.00 \quad 0.016$

1.13

0.017

0.020

1.29
3.73

0.059

Sum of pressure errors:

18.46

psia

Sum squared pressure errors:

94.03

psia

Sum of relative errors:

0.296

Sum squered relatipe ezrors: 0.021 
WSRC-TR-93-0127

"Interp.out" File for AC4M Step 29

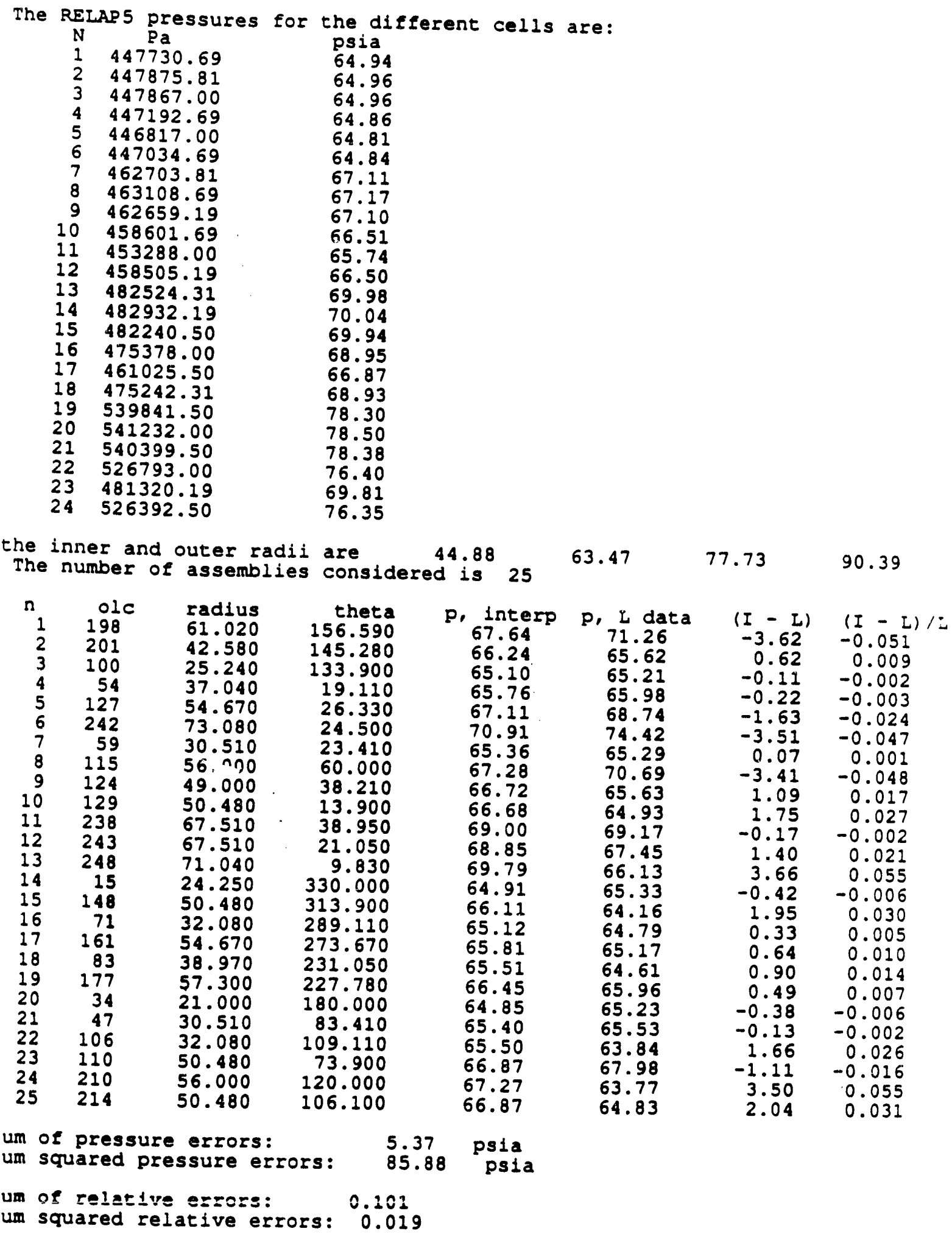


WSRC-TR-93-0127

\section{"Interp.out" File for AC4M Step 44}

$\begin{array}{ccc}\text { The RELAP5 pressures for the different cells are: } \\ \text { N } & \text { Pa } & \text { psia } \\ 1 & 449263.50 & 65.16 \\ 2 & 449767.50 & 65.16 \\ 3 & 449137.50 & 65.14 \\ 4 & 448617.00 & 65.07 \\ 5 & 448681.00 & 65.08 \\ 6 & 448981.19 & 65.12 \\ 7 & 464419.50 & 67.36 \\ 8 & 464136.31 & 67.32 \\ 9 & 461113.00 & 66.88 \\ 10 & 455250.00 & 66.03 \\ 11 & 460125.00 & 66.74 \\ 12 & 463466.19 & 67.22 \\ 13 & 484535.19 & 70.28 \\ 14 & 483613.00 & 70.14 \\ 15 & 477869.19 & 69.31 \\ 16 & 463079.69 & 67.16 \\ 17 & 477088.31 & 69.20 \\ 18 & 483217.50 & 70.08 \\ 19 & 542587.00 & 78.70 \\ 20 & 541222.00 & 78.50 \\ 21 & 529616.50 & 76.81 \\ 22 & 483568.50 & 70.14 \\ 23 & 529133.50 & 76.74 \\ 24 & 541122.00 & 78.48\end{array}$

\begin{tabular}{|c|c|c|c|c|c|c|c|}
\hline $\begin{array}{l}\text { he } \\
\text { The }\end{array}$ & $\begin{array}{l}\text { er a } \\
\text { mber }\end{array}$ & assemb & $\begin{array}{l}\text { are } \\
\text { consi }\end{array}$ & $\begin{array}{ll}4.88 \\
\text { is } 25\end{array}$ & 63.47 & 77.73 & 90.39 \\
\hline $\begin{array}{l}n \\
1 \\
2 \\
3 \\
4 \\
5 \\
6 \\
7 \\
8 \\
9 \\
10 \\
11 \\
12 \\
13 \\
14 \\
15 \\
16 \\
17 \\
18 \\
19 \\
20 \\
21 \\
22 \\
23 \\
24 \\
25\end{array}$ & $\begin{array}{r}01 c \\
198 \\
201 \\
100 \\
54 \\
127 \\
242 \\
59 \\
115 \\
124 \\
129 \\
238 \\
243 \\
248 \\
15 \\
148 \\
71 \\
161 \\
83 \\
177 \\
34 \\
47 \\
106 \\
110 \\
210 \\
214\end{array}$ & $\begin{array}{l}\text { radius } \\
61.020 \\
42.580 \\
25.240 \\
37.040 \\
54.670 \\
73.080 \\
30.510 \\
56.000 \\
49.000 \\
50.480 \\
67.510 \\
67.510 \\
71.040 \\
24.250 \\
50.480 \\
32.080 \\
54.670 \\
38.970 \\
57.300 \\
21.000 \\
30.510 \\
32.080 \\
50.480 \\
56.000 \\
50.480\end{array}$ & $\begin{array}{r}\text { theta } \\
156.590 \\
145.280 \\
133.900 \\
19.110 \\
26.330 \\
24.500 \\
23.410 \\
60.000 \\
38.210 \\
13.900 \\
38.950 \\
21.050 \\
9.830 \\
330.000 \\
313.900 \\
289.110 \\
273.670 \\
231.050 \\
227.780 \\
180.000 \\
83.410 \\
109.110 \\
73.900 \\
120.000 \\
106.100\end{array}$ & $\begin{array}{l}\text { p. interp } \\
67.26 \\
66.21 \\
65.27 \\
66.02 \\
67.39 \\
71.31 \\
65.59 \\
67.48 \\
66.94 \\
67.03 \\
69.26 \\
69.25 \\
70.38 \\
65.20 \\
66.83 \\
65.54 \\
66.79 \\
65.64 \\
66.37 \\
65.06 \\
65.60 \\
65.67 \\
67.05 \\
67.22 \\
66.94\end{array}$ & $\begin{array}{l}\text { P. L data } \\
69.52 \\
65.77 \\
65.63 \\
66.17 \\
69.05 \\
75.53 \\
65.49 \\
71.26 \\
65.33 \\
65.02 \\
69.74 \\
67.53 \\
66.80 \\
65.63 \\
65.48 \\
64.03 \\
66.73 \\
65.53 \\
65.19 \\
66.07 \\
65.77 \\
64.86 \\
68.77 \\
64.80 \\
65.39\end{array}$ & $\begin{array}{r}(I-I) \\
-2.26 \\
0.44 \\
-0.36 \\
-0.15 \\
-1.66 \\
-4.22 \\
0.10 \\
-3.78 \\
1.61 \\
2.01 \\
-0.48 \\
1.72 \\
3.58 \\
-0.43 \\
1.35 \\
1.51 \\
0.06 \\
0.11 \\
1.18 \\
-1.01 \\
-0.17 \\
0.81 \\
-1.72 \\
2.42 \\
1.55\end{array}$ & $\begin{array}{c}(I-I) /= \\
-0.033 \\
0.007 \\
-0.005 \\
-0.002 \\
-0.024 \\
-0.056 \\
0.001 \\
-0.053 \\
0.025 \\
0.031 \\
-0.007 \\
0.025 \\
0.054 \\
-0.007 \\
0.021 \\
0.024 \\
0.001 \\
0.002 \\
0.018 \\
-0.015 \\
-0.003 \\
0.012 \\
-0.025 \\
0.037 \\
0.024\end{array}$ \\
\hline
\end{tabular}

Sum of pressure errors: 


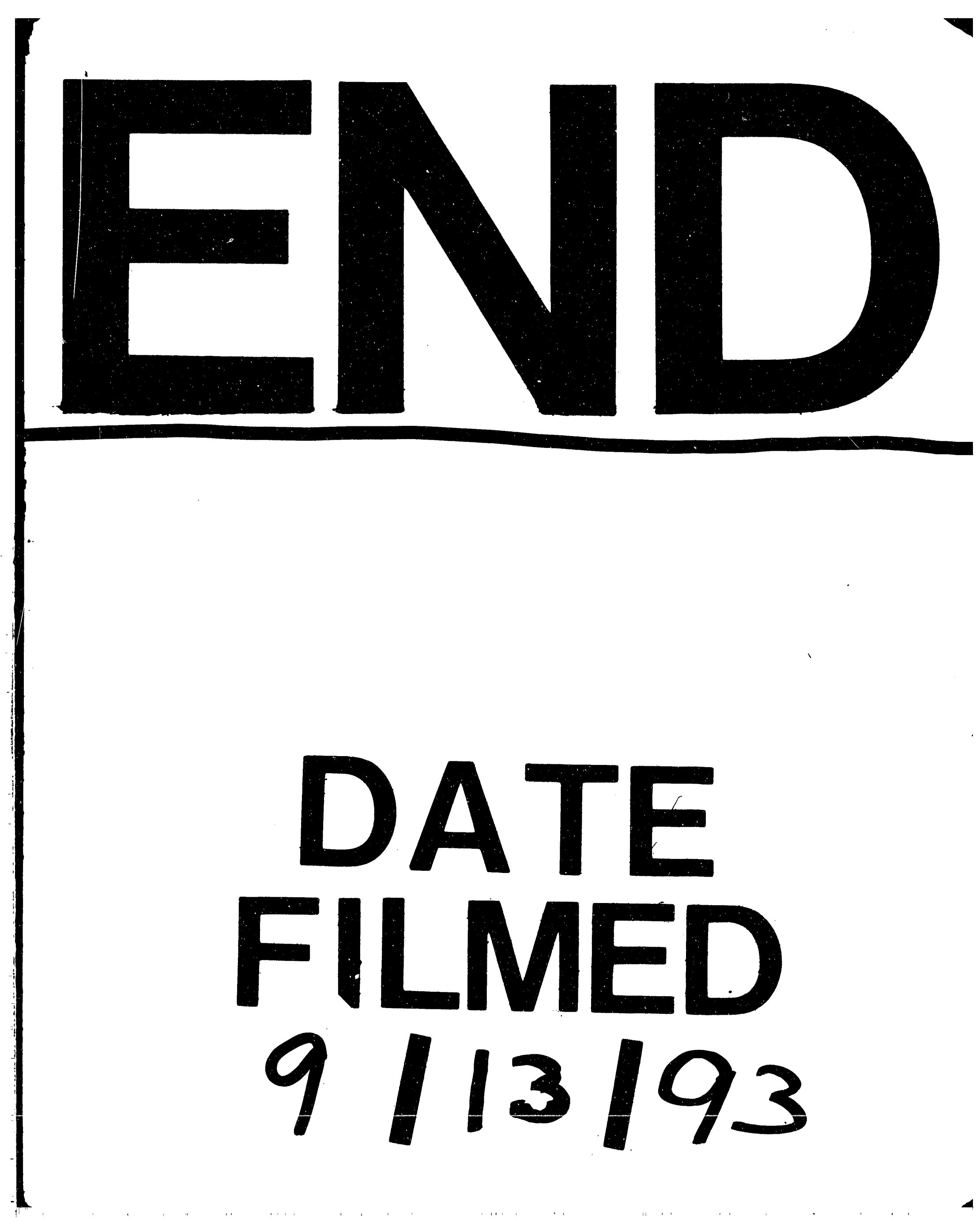




$$
\Gamma
$$

